\title{
Re-conceptualizing Critical Subjectivity and Identity in Critical Regionalism: Phenomenological Inputs
}

\section{Jin BAEK}

Department of Architecture and Architectural Engineering, Seoul National University, Seoul, Korea

\begin{abstract}
Critical regionalism has been consistently influential in architecture since the 1980s. While acknowledging its contribution to the discipline of architecture, this article inquires into two co-related issues in critical regionalism as elaborated upon by Kenneth Frampton: critical subjectivity and identity. Regarding critical subjectivity, critical regionalism demands one to stand critical of both tradition and technological development. It assumes that one can locate herself in a neutral zone unshackled from both conditions so that she can make an unbiased judgment. This article criticizes this form of subjectivity by illuminating the situated nature of the subject in the continuity of tradition within which one always stands. The second issue is identity. Keeping the identity of a region through architecture is accepted as a rule in critical regionalism. However, how we shall understand the identity is unclear. This article introduces a notion of identity as rooted in the dialectics of opposites, and demonstrates it by referring to Le Corbusier's architecture and Tetsuro Watsujis philosophy of climate. The objective of this series of inquiries is not to shake the validity of critical regionalism, but to renew and extend its significance for contemporary architecture.
\end{abstract}

Keywords : Critical Subjectivity, Identity, Tradition, Dialectics of Opposites, Climate

\section{INTRODUCTION}

Since the 1980s, critical regionalism has consistently been an influential architectural idea. As is well-known, the term was first coined by two Greek scholars, Alex Tzonis and Liliane Lefaivre, who contributed "The grid and the pathway: An introduction to the work of Dimitris and Susana Antonakakis" to Architecture in Greece (Alex Tzonis and Liliane Lefaivre, 1981). Kenneth Frampton picked up this term in "Towards a Critical Regionalism: Six Points for an Architecture of Resistance," in The Anti-Aesthetic: Essays on Postmodern Culture edited by Hal Foster (Frampton, 1983). Frampton discovered and advocated many architects including Tadao Ando as practicing in the tenor of critical regionalism. Numerous workshops and symposia contributed to the circulation of the idea. Its influence did not remain in architecture alone. In "Who Sings the Nation-State?: Language, Politics, Belonging" Judith Butler and Gayatri Chakravorty Spivak, leading critics in literature, prescribed critical regionalism as a strategy to oppose conservative

Corresponding Author: Jin Baek, Professor

Department of Architecture and Architectural Engineering,

Seoul National University

Daehak-dong, Gwanak-gu, Seoul, 151-744, Korea

Tel :+82 28807079 e-mail: jub34@snu.ac.kr

This is an Open Access article distributed under the terms of the Creative Commons Attribution Non-Commercial License (http://creativecommons. org/licenses/by-nc/3.0/) which permits unrestricted non-commercial use, distribution, and reproduction in any medium, provided the original work is properly cited. nationalism (Butler and Spivak, 2007).

The objective of this article is to revisit critical regionalism as expounded by Frampton to probe into its potentials for contemporary architecture. Specifically, I'd like to raise two issues which I believe were not fully explored in critical regionalism: critical subjectivity and identity. To be sure, the discussion of the issues is not to shake the validity of critical regionalism but to extend its significance further into the contemporary period. This article is not the first criticism of critical regionalism. Indeed, its significant criticism has already been presented. In his "The Concept of Regionalism" (Colquhoun, 1997), Alan Colquhoun traced the origin of the discourse of the identity of a region from romanticism that sought to differentiate culture from civilization in Germany during the nineteenth century. He also pointed out the political danger in which seemingly a naïve search for the identity of a region is appropriated by conservative politics including ultra nationalism. While acknowledging the originality and legitimacy of Colquhoun's well-articulated criticism, I believe it does not deal with the two issues. It is this reason that I embark on probing into the potential of critical regionalism by reflecting on two of its basic premises. In ruminating upon them, I base my arguments on precepts drawn from several phenomenological thinkers both in the West and East Asia including Martin Heidegger (1889-1976) and Tetsuro Watsuji (1889-1960).

\section{PARADOX OF CRITICAL SUBJECTIVITY}

What goes unexplained, but seems to be simply accepted, in critical regionalism is the meaning of the term 'critical.' What does 
'critical' mean? One could characterize 'critical' simply as 'standing against.' This seems to work. 'Critical regionalism' stands against: vernacular architecture for its antiquarian nature; scenographic architecture for its shallow and superficial plasticity; technocratic futurism; and lastly aestheticism. Still, however, the meaning of 'critical' itself remains unsatisfactory.

A more convincing sense of 'critical' elicited from critical regionalism as discussed by Frampton is that the term signifies one making a conscious choice, which is not governed by any exterior regulation, instruction or prejudice, but based upon one's own free reflection. This version of 'critical' rooted in the ideal of the Enlightenment confronts with doubt any prejudice, convention, authority, and tradition. One must stand free of this "selfincurred tutelage" (Kant, 1985, p.3) and follow the lead of rational reflection. The nature of freedom in this methodological doubt is radical in that it seeks freedom not within conditions, but from conditions. Equipped with reason, the author confronts the hectic transformation of the world in which technological development originating largely from the West and the tradition of a region are inextricably intermingled. He or she overcomes both vernacular nostalgia and technocratic futurism in order to find a synthesis in such a way that universal technology is adopted, while not nullifying the specific identity of a region.

Butler and Spivak's subversive call for the intentional destruction of borders and boundaries in the area of literature carries the conception of the subject aforementioned. The one who conducts the play of mixing, shuffling and suturing assumes a hegemonic subject who knows what operates as the constituents of a national identity, who keeps himself or herself at a distance from the identity, and who makes an intentional play out of it. At the level of architecture, the figure corresponding to Butler and Spivak's insubordinate practice would be Arata Isozaki. Since his tangential involvement with metabolism, Isozaki presented a series of images of ruins including Future City (1962) in which the ruins of Doric

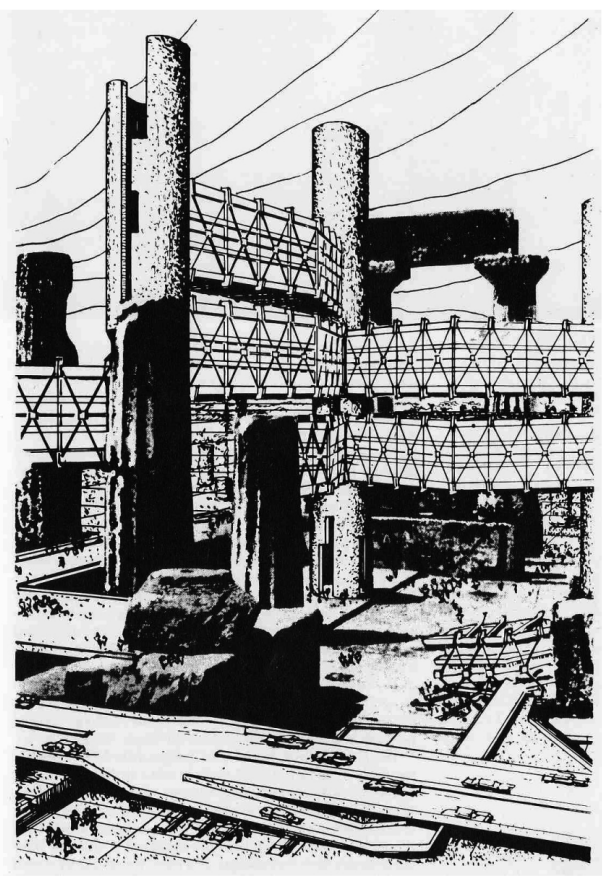

Figure 1. Arata Isozaki, Future City, 1962 (Courtesy of Arata Isozaki and Associates) orders and the debris of metabolist structure were intermingled (Figure 1). His Tsukuba Center is another example (Figures 2,3) commissioned by the National Housing and Urban Development Public Corporation. Isozaki betrayed the governmental expectation that the building should express a new Japanese identity as a major leader in technology. He did this by playfully combining vocabularies borrowed from the West such as the piazza of Campidgolio by Michaelanzelo di Lodovico Buonarroti Simoni (1475-1564) and the columns at the portico of the House of the Director at the Royal Saltworks at Arc-et-Senans by Claude Nicolas Ledoux (1736-1806).

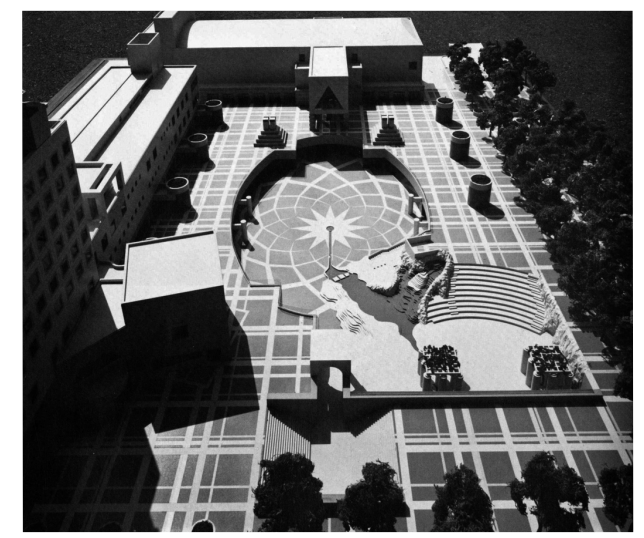

Figure 2. Arata Isozaki, Tsukuba Center, 1983 (Courtesy of Arata Isozaki and Associates)

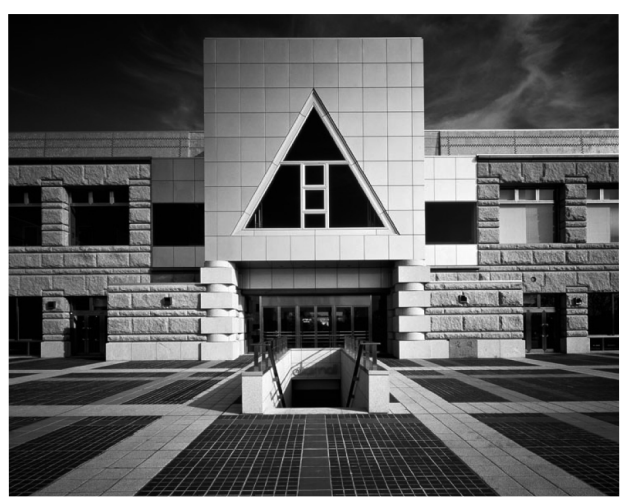

Figure 3. Arata Isozaki, Tsukuba Center, 1983 (Photograher: Ishimoto Yasuhiro, Courtesy of Arata Isozaki and Associates)

The question I would like to raise at this moment is this: Is the heroic subjectivity of reflection that can stand at the outside of both tradition and technological development so that he or she can make a disinterested judgment possible? Put differently, is it possible for the subject to equip himself or herself with methodological doubt that stands in a neutral zone, or a void, not being part of tradition? Or, put it another way, can we objectify tradition as an entity we can manipulate? Lastly, does Isozakis playful mixture of the historical vocabularies from the West built on an East Asian land verify him as standing in a zone that belongs neither to East Asia nor to the West?

The reason I pose this question is to point out the fact that critical subjectivity that conducts the methodical doubt emerges from the assumption that one can stand outside of both tradition and technological transformation. There have been many attempts to 
dismantle such conceptions of the masterful subject particularly in post-structuralism and psychoanalysis. One may argue that Isozakis practice proves the possibility of the critical subjectivity that stands in a neutral zone. However, Isozaki's case does not really prove this. What he conducts in the Tsukuba Center is not much different from the attitude towards history retained in what was called historicism of the nineteenth century (Figure 4). An architect of the century combined freely formal vocabularies from different regions, periods and styles, formulating eclecticism. History is seen as the inventory of formal and spatial vocabularies to select from. In this process, one is locked in an illusion that he or she is above history, not being part of any tradition. Likewise, Isoazaki combined vocabularies from the sixteenth century and late nineteenth century. In this case, it is just more interesting and provocative, as it is taking place in an East Asian country.

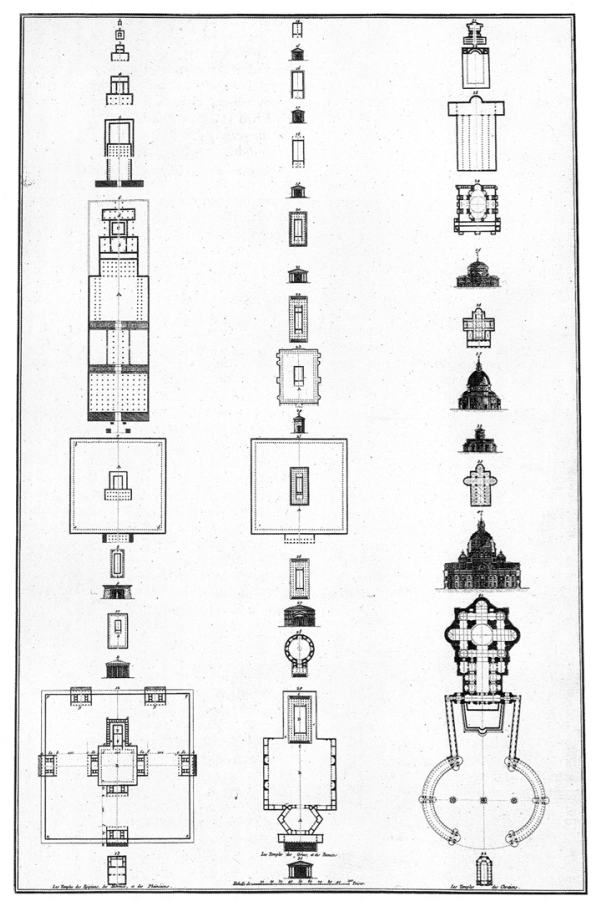

Figure 4. Jean Nicolas Louis Durand

(Scource: Durand, Recueil et parallele des edifices de tout genre)

While I understand that there are sometimes insurmountable gaps among the views about subjectivity, I'd like to introduce a conception of the subject that is diametrically opposite to the position of critical subjectivity. This conception was developed in the area of phenomenology and was extensively illuminated in hermeneutics by Hans Georg Gadamer (1900-2002). Gadamer disapproved of the claim that the subject can stand in a neutral zone, or the zone of nowhere. Rather, following Martin Heidegger's (1889-1976) idea of the thrownness (Geworfenheit) of Dasein, Gadamer claimed that the subject always stands on a horizon and is situated especially in the continuity of tradition. According to Gadamer, in order for the hermeneutic moment of one's encounter with the other to arise, one's subjectivity voluntarily opens its horizon for a new possible expansion, rather than holds fast to it, so that the other comes forward and reveals itself. This does not mean, however, that one's subjectivity has been disregarded or nullified. Gadamer claimed that "this kind of sensitivity involves neither 'neutrality' with respect to content nor the extinction of one's self, but the fore-grounding and appropriation of one's own fore-meanings and prejudices" (Gadamer, p. 269, pp. 297-299). Being part of the fore-meanings, tradition forms an essential ground in one's understanding a phenomenon. Gadamer went on to claim that "belonging to tradition" is not a subjective emotional identification with the past like sympathy, nor the objectifying and reifying of it as sheer other; it "belongs just as originally and essentially to the historical finitude of Dasein as does its projectedness towards future possibilities of itself" (Gadamer, p. 282). The following words further clarify Gadamer's conception of tradition:

Our usual relationship to the past is not characterized by distancing and freeing ourselves from tradition. Rather, we are always situated within traditions, and this is no objectifying process - i.e., we do not conceive of what tradition says as something other, something alien. It is always part of us, a model or exemplar, a kind of cognizance that our later historical judgment would hardly regard as a kind of knowledge but as the most ingenuous affinity with tradition. (Gadamer, p. 282)

In this context, Gadamer criticized the European intellectual legacy of the Enlightenment that condemned tradition simply as a case of prejudice that prevents one from seeing a phenomenon in an uninvolved and objective manner. For Gadamer, the objective probing into a matter can lead to the accumulation of knowledge, but not understanding (Verstehen). Knowledge seeks a truth which is valid for anybody in any part of the world and in any moment of history, like the answer to a mathematical equation. Understanding (Verstehen) is different. In order for a person to come to the level of understanding a phenomenon, there must arise a fusion of horizons between the personality, character and experience of the person, on one hand, and, on the other, the phenomenon. Understanding in this sense is an existential event in which what matters is how completely one comes to be united with the horizon unfolded by the phenomenon itself. In knowledge, there are right and wrong; in understanding, there exist different degrees ranging from indifference to a complete empathy.

There is another thinker who illuminated the process of understanding by using a metaphor similar to the fusion of horizons: Kitaro Nishida (1870-1945), the father of the Kyoto Philosophical School who expounded the idea of the horizon of nothingness'. In his theory, while implied, Gadamer never used the expression of the subjectivity of the non-I. In this sense, his thinking still emerged from the legacy of the western intellectual history, in which the I is a never-doubted a priori category. In contrast, breaking the pre-conceived solidity of the I, Nishida introduced the subjectivity of 'the non-I'-sometimes called 'the ego-less I'from which the I as the subject emerges. Like Gadamer, Nishida, in his theory of empathy, saw the moment of understanding as one coming to be united with the horizon opened up by a phenomenon, a text, a work of art and so forth. That one comes to a complete unity with the horizon of a phenomenon indicates the voluntary openness of the I that is ready to accept what is unfolding. This voluntary openness of the I is none other than the subjectivity of the non-I. For Nishida, the highest moment of understanding 
comes at the moment when one's subjectivity becomes completely nothing so that one is fully filled with the efficacy and atmosphere of a phenomenon.

Is Nishida's subjectivity of the non-I an intellectual fabrication? Or, how can we understand it in concrete terms? What Nishida was discussing is not an intellectual fabrication. Indeed, at the basis for our mundane daily perception is a hint at the subjectivity of the non-I. When one opens a window on a cold morning of winter, the coldness is immediately felt. It does not stop at one's skin, but proceeds further to imbue his or her depth with coldness. To cite another example, there is an atmosphere of a room such as the heat of a debate. As one enters it, he or she is immediately imbued by it. The atmosphere is first, and then there is the subject who finds himself feeling the atmosphere. The division between the subject who feels the atmosphere and the atmosphere itself is posterior to the moment in which he is in the atmosphere and becomes part of it. Nishida called this level of perceptual engagement with a phenomenon "Ur-thinking" and "the cogitation of cogitation" (Nishida, 1947, p. 123, p. 126). Again, out of this emerges an abstraction, or if you like, a reflection, in which the subject and the object of perception co-emerge. The division between the I who conducts reflection and the object of reflection is possible only when the intertwined bond between the two is acknowledged as an a priori condition. Reflection emerges as the result of the complete acceptance. Put differently, the reflection of who I am presupposes a state in which the I is intertwined with the outside phenomenon. Accordingly, this acceptance conducted at the level of the non-I is pre-critical, not uncritical.

There is a fact worth further discussion. The notion of the non-I, that is implied in Gadamer's theory of understanding and explicitly discussed in Nishidas theory of empathy, is proposed as a way of overcoming the ideal of complete objectivity cherished in the tradition of the Enlightenment and its legacy in science and critical theory. Interestingly, however, the notion of the non-I and complete objectivity have something in common. Both are similar to each other in that they seek to remove any subjective prejudice that would distort the reality of a phenomenon. It is for this reason that Maurice Merleau-Ponty (1908-1961), another great thinker in the tradition of phenomenology, praised the potential latent in the way science operates (Merleau-Ponty, 1968, pp. 181-182). Science's ideal is to maintain complete objectivity before a phenomenon. In other words, the perceiver, or the scientist, does not impose any personal value, idea or perspective upon the phenomenon so that the phenomenon itself reveals what it is. In a way, borrowing Nishida's terminology, the I, or the perceiver, becomes nothing. He or she is there, but, in a sense, is not there either. Science's principle of complete objectivity can be seen as a version of the non-I. Despite this common ground between the non-I and complete objectivity, for Merleau-Ponty, they turn out eventually to be different. First, the situation observed under the condition of complete objectivity is not the situation of the everyday, but an experiment that is artificially staged. Second, there is a more significant point. For Merleau-Ponty, the subjectivity of the non-I indicates a pre-critical, complete acceptance of a phenomenon. In contrast, complete objectivity in the tradition of the Enlightenment never forsakes the entrenched habit of doubting in order to keep its aloofness and to stand in a zone of neutrality. Two positions share a common starting point. However, their ultimate destinations are diametrically opposite to each other.

\section{IDENTITY: DIALECTICS OF OPPOSITES}

The next issue I'd like to discuss is the notion of identity. A fundamental composition based upon which critical regionalism understands the problems of architectural and urban problems is the dichotomy between universality of the technological development and particularity of a region. Its goal is to embody and express the identity of a region, while utilizing potentials of universal techniques. But, the question is how we shall understand the identity of a region. A position that sees the identity of a region as consisting in the specificity of the region composed of its vernacular architecture, folksongs, dancing, music, customs, and so forth more or less falls to the category of essentialism. As Colquhoun pointed out in reference to the Socialist movement of Germany, a search for an identity of a region this way is often played by conservative politics. It is motivated by a political situation in which a people or a nation faces a need to reestablish or even forge an identity for the consolidation and unity among its members. Colquhoun's criticism of critical regionalism does not seem to be fully justifiable, though. Critical regionalism was also aware of the political predicament Colquhoun pointed out. At the very least, it sought to overcome regionalism by accepting universal techniques in such a way that the identity of the region was not compromised. However, it appears true that critical regionalism did not clarify then how we shall understand the identity of a region beyond essentialism that sees identity as inherent within the boundary of a region.

As a way of overcoming essentialism, I'd like to introduce a dialectical notion of identity. There is a critical point of difference between essentialism and the dialectical notion of identity. In the former, one is self-sufficient with no necessity to engage with the other. In contrast, the dialectical notion of identity is possible only when one is engaged with the other. The aforementioned discussion of the non-I as the mode of subjectivity is actually related to this dialectical notion of identity. The sense of the I, or the identity of the I, is co-emerging with the other. The feeling of a cold concrete wall, as an architect put it, gives rise to the self-awareness of the I as a being of warmth. In this fashion, the I and the cold wall formulate a corporeal fabric in which two opposites-warmth and cold-reciprocate. This dialectical nature of the identity confirms that indeed the depth of the I is empty to operate as a capacity to interact with what is offered by the world. Likewise, the identity of a building is not in itself, but in its relationship with what it is not. Extending this further, the identity of a region is not in itself, but in its relationship with what it is not.

To concretize my argument, I'd like to introduce Le Corbusier's (1887-1965) sketches of the Acropolis. In the first sketch (Figure 5), Le Corbusier puts the Propylaea a bit on the right side so that a space can be opened up in the central part of the canvas. Because of this openness, a distant horizon miles away from the hill of the Acropolis comes in to the heart of the hill. This way, Le Corbusier connects the raised planarity of the hill with the distant horizon of the Piraeus at the Saronic Gulf (Figure 6). In this process, Le Corbusier bypasses the middle ground, or what exists between the Acropolis and the sea, which is the cityscape of Athens. Now, the fore-ground and the far-ground are immediately brought together. 


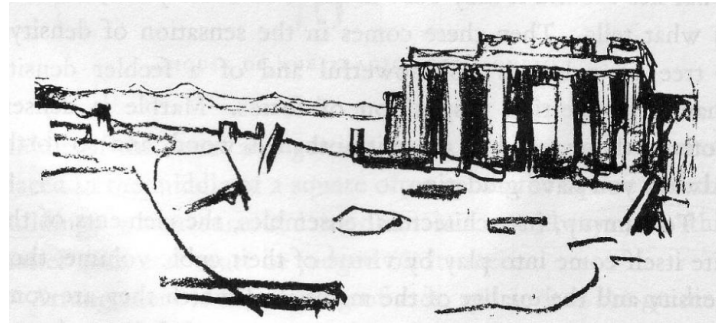

Figure 5. Le Corbusier's Sketch on the acropolis (Scource: Le Corbusier, Towards a New Architecture)

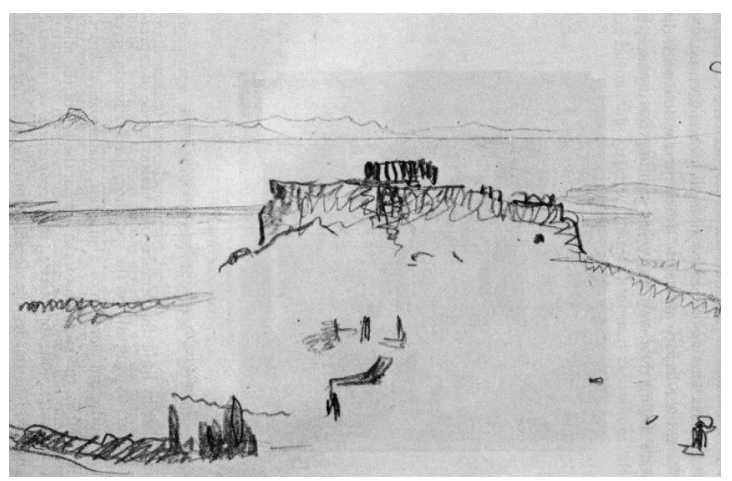

Figure 6. Le Corubusier's Sketch for the Acropolis (Scource: Le Corbusier, Towards a New Architecture)

What is the purpose of this invitation of the distant horizon to the depth of the hill? The horizon that is uncovered in Le Corbusier's sketches completes the significance of the temple on the hill. The verticality of the temple is contrasted with the horizontality of the sea. The unmoving silence of the stony temple is contrasted with the movement of boats on the sea and the fluidity of the water. The rugged roughness of the rocky hill is contrasted with the softness of the Mediterranean water. Opposite qualities are joined to each other: verticality and horizontality, unmoving silence and floating-around, and roughness and softness. What is here in the hill comes to be animated by what is not here, but what is out there in the sea. In order to reinforce the character of what is here, Le Corbusier engages with what is out there. The following words by Le Corbusier illuminate to a degree what kind of relationship he was intending to create in these sketches. One day, he was strolling in the beach of Brittany, and this is what he wrote of the experience:

I was walking and suddenly stopped. Between my eyes and the horizon a sensational event has occurred: a vertical rock, in granite is there, upright, like a menhir; its vertical makes a right angle with the horizon. Crystallization, fixation of the site. This is a place to stop, because here is a complete symphony, magnificent relationships, nobility. The vertical gives the meaning of the horizontal. One is alive because of the other" (Le Corbusier, Precisions, p. 75).

The meaning of the vertical is not in itself, but in its relationship with its opposite, the horizontal. A quality a building is trying to embody is not complete, until it engages with what it is not, until it forms a dialectical relationship with what it is not. Accordingly, identity is not in itself, but in its dialectical relationship with its opposite. Identities co-emerge through their mutual contrast. It is a logic which I would like to call the dialectics of contrasted balance between opposites.

Now, l'd like to extend the notion of identity as consisting in the dialectics of opposites to the level of the identity of a region. One thinker who is important in this regard is Tetsuro Watsuji (18891960), a leading Japanese thinker of the last century. Criticizing Heidegger's Dasein as an individual being characterized lopsidedly by time at the expense of disregarding spatiality, Watsuji brought to our attention the fundamental significance of spatiality of the human being. Here the spatiality does not mean the significance of space in the scientific sense, but means what Watsuji called fudo. Fudo has been translated into climate in English. In its narrow sense, climate means the pattern of weather. However, in its extended meaning, climate means the character of the landscape, the soil, the flora and fauna of a given land, and the qualities of local natural elements such as light, wind and rainwater. In this regard, milieu, a word borrowed from French, might be a better term. For these facts, I will use fudo, climate and milieu interchangeably in this paper.

As is well-known in Sino-Japanese linguistic tradition, fudo literally means wind and earth. However, Watsuji did not treat fudo as natural environment, in which biological, physical and geographical features exert forces on human living and the human beings in turn transform the environment. For Watsuji, this manner of thinking in which man and nature are treated as two separate entities misses the more fundamental bond between man and climatic phenomena. First, fudo indicates concrete phenomena in the daily life in which, for instance, a physical movement of air is never apprehended as a scientific fact. Rather, the movement appears "as a mountain blast or the cold, dry wind that sweeps through Tokyo at the end of the winter" (Watsuji, 1961, p.5), or a spring breeze "which blows off cherry blossoms or which caresses the waves" (Watsuji, 1961, p.5). More importantly, according to Watsuji, fudo is "the agent by which human life is objectified, and it is here that man comprehends himself; there is self-discovery" in it (Watsuji, 1961, p. 14). It is this reason that "the climatic character is the character of subjective human existence" (Watsuji, 1961, p. 16). For instance, the terms like virgin land or wilderness are not indicating the nature as it is, but are already imbued with human values of culture: virgin land for its unexplored chastity, and the wilderness for its erratic untamable condition. To cite another example, one can think about warmth. Warmth is not only a physical quality of a body of air with a certain degree of temperature. It is also a quality that characterizes the relationship between man and man, or the warmth of a person towards others. The same is true of coldness.

More curiously, Watsuji pointed out the fact that a climatic phenomenon is pervasive. Put differently, it is not something that can be objectified as an entity standing in front of a perceiver. Rather, it formulates a context in which different individuals are located. The same coldness embraces one person and another, and is articulated distinctively in their hearts. This pervasive nature of a climatic phenomenon indicates that the character of the human subjectivity that corresponds to a climatic phenomenon is also collective. What we call ethos is none other than this shared character of a group of people represented by customs, norms, 
habits and styles in music, dancing, painting, architecture, theatre and so forth. Watsujis theory of climate thus establishes a platform for environmental ethics concerned with the bond between climate and cultural expressions.

In reference to the issue of identity, it is important to figure out how Watsuji came to the awareness of the fudo of his own land. It would not be wrong to claim that Watsuji was politically motivated. His theory of fudo was to counter Wilhelm Dilthey's (1833-1911) characterization of Asian art as a whole to be unsophisticatedly vital and barbarous in Die Einbildungskraft des Dichters: Bausteine für eine Poetik (The Imaginative Power of the Poet: Building Blocks for a Theory of Poetry, 1887) (Watsuji, 1961, p. 171). Assessing Wilhelm's view as erroneous, Watsuji defended the beauty of the Orient, in particular that of his own country. He might have also felt a need to establish firmly the cultural status of Japan as the country that became swiftly as strong as European colonial forces and was colonizing other Asian countries under the banner of "the Great East Asian Empire."

However, there is an important point. Unlike Nishida, who never left Japan, Watsujis study of fudo of different regions in the world and of his own country came from his extensive exposure to the climates in the world different from his own. Indeed, his classification of the climates of the world into three partsmonsoon, desert and prairie-correspond to the route of the travel that he embarked upon in order to study philosophy under the governmental auspices of the Ministry of Education. He left the port of Kobe on March 17, 1927. The ship travelled through the South China Sea, the Indian Ocean, the Arabian Sea and the Red Sea, and the cities where the ship parked along the way included Shanghai, Hong Kong, Penang, Colombo, and Aden. From the Red sea, the ship travelled through the Suez Canal and entered the Mediterranean Sea to arrive in Marseille. From Marseille, Watsuji took trains to Berlin. In addition, while studying in Germany, he travelled not only to various cities in Germany, but also to different parts of Europe including Italy, France, and England.

In this process, he was able to acquire an awareness of the fudo of his own country. By engaging with others and by being at the outside of his own land, he came to the consciousness of the characteristics of his own climate. By becoming imbued with the heat of the Indian Ocean, he came to the awareness of the bone-chilling coldness of the Japanese winter. By being exposed to the care-free clarity of nature of Italy and Greece, he came to the awareness of the uncontrollable jungles of Japan nurtured by hotness combined with humidity in summer time. In England and Germany, according to Watsuji, a foggy day is succeeded by another. In Italy and Greece, a clear day is a norm. This monotony of the European climates led Watsuji to be aware of the varieties of climatic conditions in Japan: "the cool of a summer's evening, for example, the freshness of the morning, the violent change, sufficient to bring cold at the sunset of an autumn day, the morning cold in winter, enough to shrivel the skin, and, after it, the balmy warmth of an Indian summer day" (Watsuji, 1961, p. 200).

As these facts clarify, reflection on the climate of one's own land comes through his or her engagement with other climates. Regarding this seeing of one's own by being at the outside of his or her territory, Watsuji wrote, "we ourselves face ourselves in the state of éX-sistere' (Watsuji, 1961, p. 3). Here the term éX-sistere' meaning 'standing outside,' deserves further qualification. 'EX-sistere' is a concept in phenomenology that grounds intentionality that we don't just think, but we always "think of" something. In particular, Watsuji was influenced by Heidegger's discussion of this idea in Being and Time (1927). I'd like to introduce a passage regarding é $X$ sistere' from a later writing by Heidegger, as it illuminates the idea in concrete terms:

If all of us now think, from where we are right here, of the old bridge, in Heidelberg, this thinking towards that locale is not a mere experience inside the persons present here; rather, it belongs to the essence of our thinking of that bridge that in itself thinking persists through [durchsteht] the distance to that locale. From this spot right here, we are there at the bridge-we are by no means at some representational content in consciousness. From right here we may even be much nearer to that bridge and to what it makes room for than someone who uses it daily as an indifferent river crossing. ... To say that mortals are is to say that in dwelling they persist through spaces by virtue of their stay among things and locales. And only because mortals pervade, persist through, spaces by their very essence are they able to go through spaces. . . When I go toward the door of the lecture hall, I am already there, and I could not go to it at all if I were not such that I am there. I am never here only, as this encapsulated body; rather, I am there, that is, I already pervade the space of the room, and only thus can I go through it (Heidegger, "Building, Dwelling, Thinking," 1993, pp. 358-359, Heidegger's italicizations)

Heidegger saved "thinking of" from idealism in which one would cherish an image or representation of what is not physically present. In this process, Heidegger introduced the idea of pervasiveness of the I. Instead of seeing the I as confined within the perimeter of 'here and in this body', Heidegger stated a co-presence of the I of here' and the I of there. And, the I of there is joined with a thing that is present some distance away, even in a location that is not immediately perceivable. For Heidegger, "thinking of" is thus dependent on the co-presence of the I of here and the I of there, and the co-presence between the I and the thing.

Watsujis idea of "eX-sistere" is similar to Heidegger's. "EX-sistere" is the fundamental principle of the structure of ourselves, and it is on this principle that intentionality depends" (Watsuji, 1961, p. 4). In particular, Watsuji used this term when he explained the phenomenon of feeling cold. He wrote: "when we feel cold, we ourselves are already in the coldness of the outside air" (Watsuji, 1961, p. 3). The I that is here and the I that is in the middle of coldness fashion the formula of reflection in which one sees one's own self. In other words, the discovery of who I am is possible on the basis of me being paradoxically at the outside of the confines of my own selfhood. As explained previously, the same coldness embraces one and another. This means that it is not only the I who is out in the coldness, but others, too. Watsuji thus wrote: "EXsistere' is 'to be out among other 'I's" (Watsuji, 1961, p. 4). While the relationship between one and coldness is that of intentionality, the relationship between different 'I's in the coldness is that of mutual compassion. Accordingly, in this process of reflection, 
an individual's self-discovery is not solitary or self-focused, but becomes part of "we." It is we that discover ourselves, not merely fragmented individuals.

Watsuji continued that even when one understands reflection "in its visual sense, i.e., if it is understood as to dash against something and rebound from it and to reveal oneself in this rebound or reflection, it can be argued that the word may well indicate the way our selves are exposed to ourselves" (Watsuji, 1961, p. 3). For Watsuji, his trip to the Indian Ocean created a moment in which he was in the foreign ocean and simultaneously he was there in his homeland through thinking of the homeland. The Watsuji of the Indian Ocean and the Watsuji of the homeland from which he is temporarily dislocated was the very structure of reflection of what his climate was like.

However, for Watsuji, reflection is not the highest mode of selfapprehension. In self-apprehension, according to Watsuji, our attention is not fixed at ourselves. We do not look merely at our own self. Rather, we reach out to the world. When I find myself feeling cold, this moment of self-apprehension is not an end in itself. Instead, we come to be necessarily connected with acts such as looking for more clothes. Consequently, the discovery of one's own self does not confirm the insulated interiority of the subject. Rather, it reconfirms how one is interconnected with the world. Watsuji wrote, "in this self-apprehension we are directed to our free creation" (Watsuji, 1961, p. 6). More importantly, as argued above, in the phenomenon of self-apprehension in a milieu, the I is joined with other Is. Watsuji wrote: "It is in our relationship with the tyranny of nature that we first come to engage ourselves in joint measures to secure early protection from such tyranny" (Watsuji, 1961, p. 6). Creations through the joining of different Is are the basis for what we call culture. Culture is thus "an inheritance of selfapprehension accumulated over the years since the time of our ancestors" (Watsuji, 1961, p. 6).

Architecture is also the result of the collective measures made by individuals of self-apprehension. Watsuji wrote: "Thus the determination of the architectural style of a house is an expression of the self-apprehension of man within climate" (Watsuji, 1961, p. 7). With the term style, Watsuji was not referring to the formal features of buildings. Rather he meant the manner by which architecture supports and enhances the way people live together in daily life. Architectural creation is not an individual heroic act to protect himself or herself from the whims of nature. As Watsuji noted critically, this kind of view does not escape from the formula of natural science in which the environment influences man and man in turn transforms the environment. Without understanding the dimension of self-apprehension - the fundamental bond between climate and the human being-man sees nature merely as the object of manipulation and nature is also seen as regulating human desires. Rather, one finds one's self in climate and, in this selfapprehension, man reaches out to the world to create things.

In more concrete terms, imagine a summer day in Kyoto. One finds himself or herself as soaked in hotness combined with humidity. Following Watsujis formula, he is out in the hotness and humidity, along with other 'I's. Climate is not merely something to overcome, but is the agency that gives meaning to architectural creation as a collective measure of hotness and humidity. Out of this process emerges what Watsuji called "selfless openness" (Watsuji, 1961, p. 145) of the Japanese residential architecture (Figure 7).
The selflessness of the layout emerges upon the joining of different 'I's in the midst of a climatic phenomenon in order to formulate a cross-ventilation that would remove heat and humidity effectively. This kind of openness seems radical in that typical contemporary residential architecture often shows an obsession with privacy embodied through individual rooms equipped with separate air-conditioning units and a corridor. In the "self-less openness" Watsuji discussed, privacy is not gone. Rather, privacy is not a category from the beginning, as there is no isolated 'I', but many 'I's equally exposed to the pervasive hotness and humidity.

What is significant is to figure out similarity in the pattern between the reflection of one's own self and the reflection of one's own climate. Just as one has to come out of the confines of the I in order to discover who he or she is, Watsuji came out of his own climate. The self-awareness of the region in which he was situated emerges from the viewpoint of a traveler. The climate of a region is distinctive not because it is self-sufficiently so, but because of its relationship with others. Even when Watsujis aim was to clarify what his own culture was by referring to the other, what is confirmed here is not necessarily the uniqueness of a culture with a coherent and inherent system of identity, but the dialectical structure of the identity in which one is present because of the other or one comes to be clarified because of its engagement with the other.

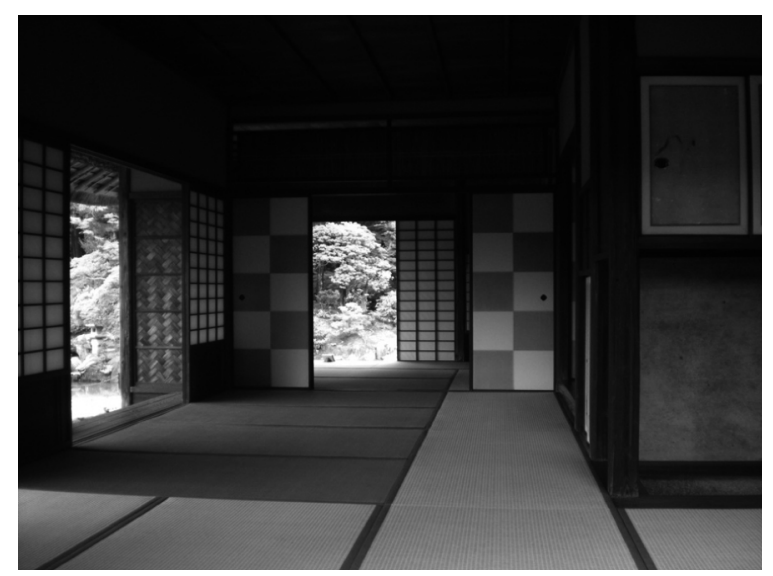

Figure 7. Flexible spatiality in Japanese traditional residential architecture (Photo by author)

\section{CONCLUSION}

Critical subjectivity on the basis of which critical regionalism operates idealizes complete objectivity. Gadamer, Nishida and Merleau-Ponty clarified, however, that the notion that one can stand in a neutral zone so that he or she can be critical of different forces is an illusion. For Nishida and Merleau-Ponty in particular, the highest form of complete objectivity is not against engagement. To the contrary, it indicates one's unconditional acceptance of the efficacy of a phenomenon, an acceptance from which the subject of reflection emerges. Nishida's notion of "the horizon of nothingness"-his ultimate philosophical achievement-indicates this level of complete dissolution of ego so that he or she becomes the instrument to be imbued by the efficacy. This subject of prereflective engagement renews the significance of tradition. When one is captured in the illusion of neutrality, he or she takes on the 
attitude of indifference as if he or she were not part of any horizon. In architecture, the practice conducted by critical subjectivity that is aloof from tradition has often led to the playful mastery of formal vocabularies belonging to different areas, cultures and eras. This playfulness concretizes itself in the form of mixing, transposing, juxtaposing, superimposing, shuffling and suturing of the vocabularies. In this regard, Colquhoun's point that a work of critical regionalism often ends up combining formal features of a local area with the technology of a non-local construction is valid.

What is connected with Gadamer and Nishida's situated subjectivity is a unique notion of identity. Identity is not something that is present within the interiority of a culture, a land, a people or a territory. Rather, it is a product of a dialectical encounter with others. Identities co-emerge in mutual contrast and dependence. It is through this process that one's identity comes to be clarified. A good example of this notion of identity was Le Corbusier's architecture. He situated a building by mapping a context in which the middle ground is dropped so that the fore-ground and the farground are joined immediately to each other. What is present in the fore-ground came to be animated not by what is present within the territory of the building, but by what is given in the far-ground. Reiterating, the identity of the building is not in itself, but in its relationship with what it is not.

At the level of the regional identity, Watsuji's discussion of climate is valuable. Watsuji's awareness of his own climate and thus of the identity of his region comes into being through his being at the outside of his own climate. This manner of apprehending the identity of a region corresponds to the logic of the dialectics of opposites in which distinctiveness of a climate is not in itself, but rather in its relationship with what it is not. While the issue of climate is discussed only in passing in critical regionalism, Watsuj's philosophy leads us to illuminate the fundamental bond between 'who we are' and climate. "Selfless openness" with which Watsuji portrayed the spatiality of Japanese vernacular houses is possible only when there arises the joining of different 'I's as standing in "ex-sistere" in the midst of a pervasive and encompassing climatic phenomenon.

Characterizing the openness of the Japanese houses with selflessness, self-apprehension and collectivity is profound. It modifies the dominant modernist view that the Japanese openness embodies functional flexibility and efficiency. It also gives rise to a lesson for the contemporary residential architecture. The sustainable performance of the Japanese houses in summer time arises upon the basis of collectivity in which individuals are joined together to formulate a 'we.' Put differently, Watsuji's elucidation offers an opportunity for us to reflect upon our habitual emphasis on privacy embodied through the configuration of individual, separate rooms connected only through a corridor. It is time to examine the following: the way we apprehend climate in contemporary architecture, in particular in reference to sustainability; the way we formulate the relationship between man and climate; and whether we stick mechanically to privacy, not understanding the fact that the collectivity of, in Watsuji's words, "selfless openness" is the basis for a proper passive sustainable performance. For Watsuji, there is no such a thing as a pure individual who would stay in an enclosed room insulated with an air-conditioner inside. Rather, the true individual is the individual of act, one who joins himself or herself with other 'I's in the process of formulating a collective measure in response to a climatic phenomenon in which he or she is situated.

\section{REFERENCES}

Butler, Judith and Spivak, Gayatri Chakravorty In "Who Sings the Nation-State?: Language, Politics, Belonging" (2007)

Colquhoun, Alan. "The Concept of Regionalism." in Postcolonial Spaces, ed. G.B. Nalbantoglu and C.T.Wong, New York: Princeton Architectural Press, 1997, pp. 13-23.

Frampton, Kenneth (1983). "Towards a Critical Regionalism: Six Points for an Architecture of Resistance." in The Anti-Aesthetic. Essays on Postmodern Culture. ed. Hal Foster, Bay Press, Port Townsen.

Gadamer, Hans-George. (1999) Truth and Method. trans. Joel Weinsheimer and Donald G.. Marshall. New York: Continuum.

Heidegger, Martin. (1962) Being and Time. trans. Macquarrie and Robinson. New York: Harper and Row.

Heidegger, Martin. (1993) "Building Dwelling Thinking" in Basic Writings. ed. David Farrell Krell. New York: Harper and Row, pp. 343-363.

Kant, Immanuel. (1985) "What is Enlightenment?" in On History, ed. Lewis White Beck, New York: Macmillan Publishing Company, pp. 3-10.

Le Corbusier (1986). Towards a New Architecture. trans. Frederick Etchells. New York: Dover Publications.

Merleau-Ponty, Maurice. (1968) The Visible and the Invisible. ed. Claude Lefort. trans. Alphonso Lingis. Evans-ton: North Western University Press.

Nishida, Kitaro. (1947) Complete Works (Nishida Kitarō zenshu), Tokyo: Iwanamishoten, 1947, vol. 6.

Tzonis, Alex and Lafaivre, Liliane (1981). "The Grid and the Pathway: An Introduction to the Work of Dimitris and Susana Antonakakis" in Architecture in Greece 15, pp. 164-178.

Watsuji, Tetsuro. (1961) Fudo (A Climate: A Philosophical Study). trans. Geoffrey Bownas, Tokyo: Ministry of Education Printing Bureau.

(Date of Submission : 2010.12.21) 